\title{
Fatal Hepatic Necrosis Associated with Parenteral Gold Therapy
}

\author{
PAUL B. WATKINS, MD, ROBERT SCHADE, MD, A. SCOTT MILLS, MD, ROBERT L. \\ CARITHERS, JR, MD, and DAVID H. VAN THIEL, MD
}

Parenteral gold therapy is widely used in the longterm management of rheumatoid arthritis. Prolonged cholestasis is a well-recognized toxic manifestation of this form of therapy and is not lifethreatening. Severe hepatocellular disease, including fatal hepatitis, was observed during the early clinical experience with chrysotherapy (1-4). However, with the possible exception of a single case (5), this form of liver injury has not been associated with gold since disposable needles and hepatitis B serologic testing have been in routine clinical use. It has therefore been suggested that these early reports represented concomitant viral hepatitis rather than an idiosyncratic reaction to gold (6).

Two patients who were receiving parenteral gold recently presented to our institutions with fulminant hepatic necrosis that could not be ascribed to hepatitis A or hepatitis B. The striking similarity of these cases suggested the strong possibility that parenteral gold contributed to the fatal liver injury.

\section{CASE REPORT}

Case 1. A 33-year-old black male with seronegative rheumatoid arthritis was admitted to a Detroit hospital on February 3, 1983, with a three-day history of right upper quadrant pain, fever, and jaundice. He noted these symptoms one day after his second injection of aurothioglucose ( $75 \mathrm{mg}$ total gold dose). His only daily medication was indomethacin $50 \mathrm{mg}$ qid, but compliance with and the duration of this therapy was not documented. He denied

\footnotetext{
Manuscript received November 3, 1986; revised manuscript received April 13, 1987; accepted June 22, 1987.

From the University of Pittsburgh, Department of Medicine Pittsburgh, Pennsylvania 15261; and Department of Medicine and Department of Pathology, Medical College of Virginia, Virginia Commonwealth University, Richmond, Virginia 23298.

Address for reprint requests: Dr. Paul Watkins, $6520 \mathrm{D}$ Medical Science Research, Building I, The University of Michigan, Medical School, Ann Arbor, Michigan 48109.
}

alcohol intake or exposure to hepatitis and had no history of blood transfusions. Serum ALT, AST, and bilirubin levels were normal one month earlier.

On examination he was jaundiced and in acute distress because of right upper quadrant abdominal pain. Blood pressure was $96 / 48 \mathrm{~mm} \mathrm{Hg}$, pulse $110 / \mathrm{min}$, and respiratory rate $20 / \mathrm{min}$. Temperature was $103.4^{\circ} \mathrm{F}$. Examination of the skin revealed no rashes. Liver span could not be assessed because of exquisite right upper quadrant tenderness; splenomegaly was not evident. Neurologic examination was within normal limits.

Admission laboratory studies included a hemoglobin of $7.3 \mathrm{~g} / \mathrm{dl}$; WBC 11.7 cells $/ \mathrm{mm}^{3}$ with 49 polys, 21 bands, and no eosinophils; platelets 315,000 cells $/ \mathrm{mm}^{3}$; AST 3430 IU/liter; ALT 2380 IU/liter; LDH 2080 IU/liter; bilirubin $20.7 \mathrm{mg} / \mathrm{dl}$; and alkaline phosphatase $342 \mathrm{IU} / \mathrm{liter}$. The prothrombin time was prolonged by $4 \mathrm{sec}$, BUN was 21 $\mathrm{mg} / \mathrm{dl}$, and creatinine was $1.6 \mathrm{mg} / \mathrm{dl}$. On the second hospital day the patient's hemoglobin fell to $6.1 \mathrm{~g} / \mathrm{dl}$ and melena was noted. The bilirubin level climbed to $46 \mathrm{mg} / \mathrm{dl}$ on the fourth hospital day. Abdominal sonography revealed no obstruction of the biliary tree. On the fourth hospital day ascites was noted. On the sixth hospital day the patient became lethargic; arterial ammonia was 150 $\mu \mathrm{M} / \mathrm{iter}$. On the seventh day urine output ceased and the patient developed pulmonary edema. Hemodialysis was begun, and the patient was flown to the University of Pittsburgh for possible liver transplantation 10 days after initial presentation.

On admission to Presbyterian University Hospital, the patient required immediate intubation and positive endexpiratory pressure ventilation. Dialysis was continued, and periodic blood transfusions were given for persistent gastrointestinal bleeding. Laboratory studies revealed a white blood cell count of 18,900 cells $/ \mathrm{mm}^{3}$ with a left shift ( $2 \%$ eosinophils), platelets 20,000 cells $/ \mathrm{mm}^{3}$, alkaline phosphatase $24 \mathrm{IU} /$ /iter, ALT $10 \mathrm{IU} /$ liter, total bilirubin $32.1 \mathrm{mg} / \mathrm{dl}$, arterial ammonia $63 \mu \mathrm{M} / \mathrm{liters}$, and prothrom-

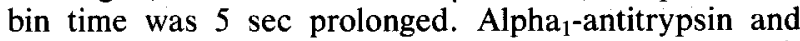
ceruloplasmin levels were normal. Hepatitis A IgM antibody was negative, and $\mathrm{HB}_{\mathrm{s}} \mathrm{Ag}$, anti- $\mathrm{HB}_{\mathrm{c}}$, and anti- $\mathrm{HB}_{\mathrm{s}}$ were absent.

The patient underwent orthotopic liver transplantation on February 14, 1983, two weeks after the onset of his illness. The resected liver weighed $2000 \mathrm{~g}$. Microscopic 
examination revealed hepatocellular drop-out in the centrilobular region and portal-central bridging necrosis (Figure 1). On February 17, the patient was reexplored due to persistent intraabdominal bleeding. He did not regain consciousness and died soon after the second procedure.

Case 2. A 23-year-old black male presented to the Medical College of Virginia on September 10, 1982, with a one-week history of progressive malaise, anorexia, and jaundice. He admitted to drinking one six pack of beer on weekends, but denied hepatitis contact or intravenous drug abuse and had never received a blood transfusion. The patient's only daily medication was ibuprofen $400 \mathrm{mg}$ qid which he had been taking intermittently for several months. He had been started on weekly aurothiomalate injections two months before for seronegative rheumatoid arthritis and had received a total of $385 \mathrm{mg}$ gold.

During the examination, the patient was pleasant and cooperative and did not appear ill. His blood pressure was $130 / 80 \mathrm{~mm} \mathrm{Hg}$, pulse $56 / \mathrm{min}$, and respiratory rate $20 / \mathrm{min}$. He was afebrile. There were no stigmata of chronic liver disease and no rashes, petechiae, echymoses, or edema. He had mild right upper quadrant tenderness with a liver span of $13 \mathrm{~cm}$ without a palpable edge. No spleen was felt. His mental status was normal, and asterixis was not present.

Admission laboratory studies included a bilirubin of 7.7 $\mathrm{mg} / \mathrm{dl}$, AST 3414 IU/liter, ALT 2760 IU/liter, alkaline phosphatase $397 \mathrm{IU} /$ liter, albumin $3.4 \mathrm{~g} / \mathrm{dl}$, cholesterol $133 \mathrm{mg} / \mathrm{dl}$, BUN $4 \mathrm{mg} / \mathrm{dl}$, creatinine $0.4 \mathrm{mg} / \mathrm{dl}$, prothrombin time prolonged $6 \mathrm{sec}$, white blood cell count 5200 cells $/ \mathrm{mm}^{3}$ with $6 \%$ eosinophils, hemoglobin $13.2 \mathrm{~g} / \mathrm{dl}$, and platelet count 400,000 cells $/ \mathrm{mm}^{3}$. There was no evidence of bile duct dilatation on ultrasonographic examination. Anti-HB $\mathrm{B}_{\mathrm{s}}$ was detected. $\mathrm{HB}_{\mathrm{s}} \mathrm{Ag}$ and anti-HB were both negative.

Asterixis, lethargy, and an arterial blood ammonia level of $190 \mu \mathrm{M} /$ liter were noted on the twelfth hospital day. During the several subsequent days the patient's transaminase levels slowly fell, but the encephalopathy persisted and the prothrombin time continued to climb despite administration of exogenous clotting factors. On the seventeenth hospital day the patient required five units of blood to replace losses due to bleeding from stress ulcerations of the stomach. On the eighteenth hospital day, the patient had grand mal seizures. On the thirty-second hospital day, the patient's bilirubin was 20 $\mathrm{mg} / \mathrm{dl}$, alkaline phosphatase $174 \mathrm{IU} /$ liter, AST $94 \mathrm{IU} /$ liter, ALT $40 \mathrm{IU} / \mathrm{liter}$, albumin $2.2 \mathrm{~g} / \mathrm{dl}$, cholesterol $27 \mathrm{mg} / \mathrm{dl}$, and prothrombin time $26 \mathrm{sec}$ with control of $11 \mathrm{sec}$. The patient died on the thirty-sixth hospital day. The postmortem liver weighed $750 \mathrm{~g}$ and showed massive hepatic necrosis with focal nodules of regenerating parenchyma (Figure 2).

\section{DISCUSSION}

Jaundice has been associated with parenteral gold therapy since its first use in clinical medicine in the 1920s. The incidence of jaundice reported in the early clinical trials of crysotherapy ranged from
$0.25 \%(7)$ to as high as $9.4 \%(8)$. In addition, there were a number of early reports of fatal hepatitis in patients receiving gold (1-4). A single case of severe hepatocellular necrosis has been reported recently (5) in a patient who had been receiving gold injections for longer than six months. All other recent reports of idiosyncratic liver reactions to gold have stressed the cholestatic and benign nature of the condition. Of these 16 cases reported since 1970 (9-19), all patients became jaundiced within the first 12 weeks of treatment. Total gold doses ranged from as low as $10 \mathrm{mg}$ (13) to as high as $600 \mathrm{mg}$ (15), and thiomalate $(9-11,13,15,16,18,19)$, thiopropanol (11), and thioglucose $(14,17)$ gold salt preparations have been implicated. Most of the patients reported were only mildly symptomatic. Fever, rash, and eosinophilia were frequently, but not invariably, present. The reported biochemical parameters and histologic features were predominantly those of an intrahepatic cholestasis, and serum transaminase levels greater than 10 times the upper limit of normal were reported in only one patient (12). Resolution of jaundice was generally prolonged but eventually all but a single patient (18) recovered. This patient, however, died of pneumonia and, at autopsy, histologic evaluation of the liver revealed only "mild centrizonal congestion, necrosis and bile stasis" (18).

The two patients presented in this report do not fit the clinical pattern of gold hepatitis as recently reported. On admission to the hospital and prior to any evidence of hemodynamic instability, each patient had serum transaminase elevations that exceeded 70 times the upper limit of normal. In each patient, the liver injury proved to be fatal.

It is not possible to establish a direct causal relationship between parenteral gold and the fatal hepatitis reported here even though each patient had recently begun treatment with this agent. In addition to gold, each patient was using a medication which has occasionally been reported to cause hepatitis $(20,21)$. Thus, drug-induced hepatitis due to indomethacin and ibuprofen is possible. In addition, in neither case could non-A, non-B viral hepatitis be completely excluded, as there is no reliable serologic marker for this condition; however, neither patient had a history of recent dental work, blood transfusions, homosexuality, or illicit drug use.

Despite these reservations, the striking similarity of these two cases, seen at different institutions, and their similarity to the older reports of fatal 


\section{HEPATIC NECROSIS AND GOLD THERAPY}
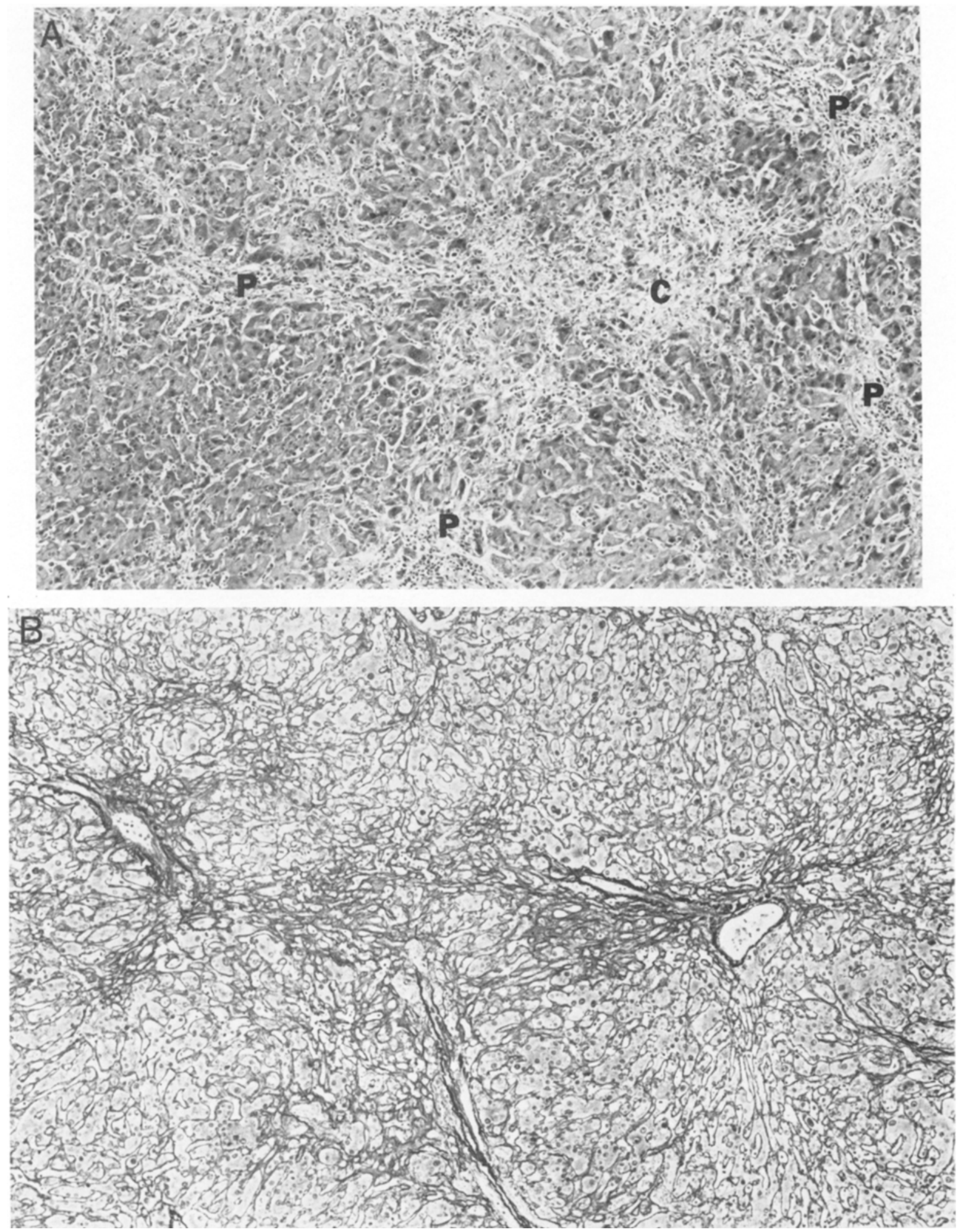

Fig 1. Case 1, liver: (A) There is complete drop-out of hepatocytes in the centrizonal region of the lobule with portal-central bridging necrosis. Lymphocytes are scattered throughout the lobule. C, central; P, portal (H\&E, 25×). (B) Bridging necrosis is highlighted by reticulin collapse (Wilder's reticulin, $25 \times$ ). 

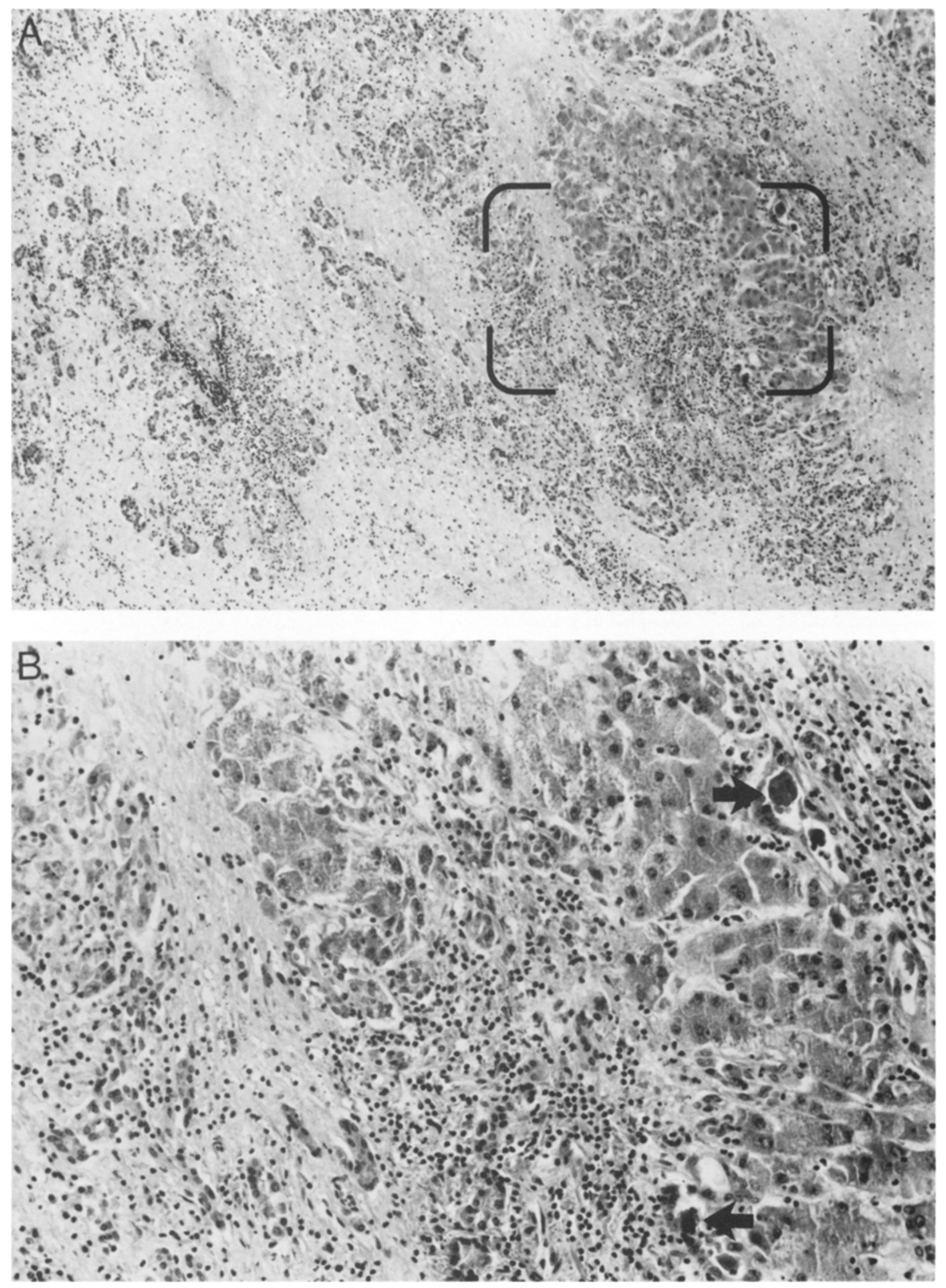

Fig 2. Case 2, liver: (A) There is panlobular necrosis with haphazardly scattered islands of viable hepatocytes. Pseudoductular proliferation is prominent in areas of necrosis. The field bracketed is seen at higher magnification in $B$ $(H \& E, 25 \times)$. (B) Clusters of viable hepatocytes are surrounded by a mixed inflammatory infiltrate composed largely of lymphocytes. Occasional bile plugs (arrows) are present (H\&E, 100×). 
hepatitis following the institution of gold therapy raise concern that they may represent severe idiosyncratic reactions to gold. It has been estimated that seven million people suffer from rheumatoid arthritis in the United States alone (22). Oral gold preparations have recently been approved by the Food and Drug Administration, and it is expected that this will result in a great increase in the use of gold in this patient population (23). Awareness of the possibility of severe hepatocellular injury resulting from the use of gold preparations alone or in combination with nonsteroidal antiinflammatory drugs may become increasingly important.

\section{SUMMARY}

Two young black male patients with seronegative rheumatoid arthritis and treated with nonsteroidal antiinflammatory agents developed fulminant hepatic necrosis following the institution of parenteral gold therapy. These cases, reported from different institutions, may represent a severe form of idiosyncratic gold hepatonecrosis. Awareness of the possible association between gold therapy and severe hepatic injury may become increasingly important as oral gold preparations become widely available.

\section{REFERENCES}

1. Langmead $\mathrm{F}$ : The gold treatment of tuberculosis. Br Med J 1:735-738, 1925

2. Driver JR, Weller JN: Untoward results from the use of gold compounds. Report of a fatal case. Arch Dermatol Syphilol 23:87-109, 1931

3. Hartfall SJ: Further observations on the gold treatment of rheumatoid arthritis. Lancet 1:1459-1462, 1936

4. Juel AJ: Dodsfald ved guldehandling i Danmark 1960-1964. Ugeskr Laeger 135:1639, 1973

5. Closa AS, Rovira EC, Lopez JVA, Gispert JS: Necrosis hepatica submassiva asocida a tratamiento con sales de oro. Gastroenterol Hepatol 6:468-470, 1983
6. Zimmerman HJ, Maddrey WC: Toxic and drug induced hepatitis. In Diseases of the Liver. L Schiff, ER Schiff (eds). Philadelphia, JB Lippincott, 1982, p. 660

7. Hartung EF: Toxic hepatitis during gold salts therapy: Its effect on the course of the rheumatoid arthritis. Med Clin North Am 30:553-561, 1946

8. Hartfall SJ, Garland HG, Goldie W: Gold treatment of arthritis. Lancet 2:838-842, 1937

9. Schenker S, Olson KN, Dunn D, Breen, MB, Combes, B. Intrahepatic cholestasis due to therapy of rheumatoid arthritis. Gastroenterology 64:622-629, 1973

10. Favreau M, Tannenbaum H, Lough J: Hepatic toxicity associated with gold therapy. Ann Intern Med 87:717-719, 1977

11. Ghishan FK, LaBreque DR, Younoszai K: Intrahepatic cholestasis after gold therapy in juvenile rheumatoid arthritis. J Pediatrics 93:1042-1043, 1978

12. Pessayre D, Feldmann G, Ulmann A, Erlinger, RS, Benhamou, JP Gold salt-induced cholestasis. Digestion 19:56-64, 1979

13. Howrie DL, Gartner JC Jr: Gold-induced hepatotoxicity: Case report and review of the literature. J Rheumatol 9:727-729, 1982

14. Lowthian PJ, Cleland LG, Vernon-Roberts B: Hepatotoxicity with aurothioglucose therapy. Arthritis Rheum 27(2):230-232, 1984

15. Edleman J, Donnelly R, Graham DN, Pearcy JS: Liver dysfunction associated with gold therapy for rheumatoid arthritis, J Rheumatol 10(3):510-511, 1983

16. Lewis D, Madhok R, Capell H: Liver dysfunction associated with gold therapy for RA. J Rheumatol 11(3):395-396, 1984 (letter)

17. Schapira D, Nahir M, Scharf Y, Pollack S: Cholestatic jaundice induced by gold salts; treatment, clinical and immunological aspects. J Rheumatol 11:843, 1984

18. Shaban MR, Golding DN, Letcher RGM: Fatal intrahepatic cholestasis and interstitial lung fibrosis following gold therapy for rheumatoid arthritis. J R Soc Med 77:960, 1984

19. Smith MD: Hepatitis and neutropenia secondary to gold thiomalate therapy for rheumatoid arthritis. Aust NZ J Med $16: 72,1986$

20. Kelsey WM, Schar JM: Fatal hepatitis probably due to indomethacin. JAMA 199:586, 1967

21. Ibuprofen (Motrin)—a new drug for arthritis. Med Lett Drug Ther 16:109, 1974

22. Gottlieb NL, Blechman W: Current trends in the treatment of rheumatoid arthritis. Am J Med Dec 30, 75(6A):1-2, 1983

23. Kaplan H: Auranofin: Bane or bonanza for the nonrheumatologist. Am J Med Dec 30, 75(6A):145-151, 1983 